\title{
The Rise of Meme Culture: Internet Political Memes as Tools for Analysing Philippine Propaganda
}

\author{
Faye Margarette G. De Leon (Corresponding author) \\ University of Santo Tomas, Philippines \\ Email: fayemargarette.deleon.ab@ust.edu.ph \\ Rachelle Ballesteros-Lintao \\ University of Santo Tomas, Philippines
}

Received: $11 / 02 / 2021$

Accepted: 28/04/2021

Published: 01/07/2021

Volume: 2 Issue: 4

How to cite this paper: De Leon, F. M. G., \& Ballesteros-Lintao, R. (2021). The Rise of Meme Culture: Internet Political Memes as Tools for Analysing Philippine Propaganda. Journal of Critical Studies in Language and Literature, 2(4), 1-13

DOI: https://doi.org/10.46809/jcsll.v2i4.70

Copyright (C) 2020 by author(s) and Global Talent Academy Ltd. This work is licensed under the Creative Commons Attribution International License (CC BY 4.0).

http://creativecommons.org/licenses/by/4.0/

(c) (i)

\begin{abstract}
This research paper was aimed at providing a thorough content analysis on memes' linguistic aspect and further understanding them in the light of their usage as political propaganda. A total of 60 memes were culled from July 2016 to December 2018. According to the memes' linguistic and visual organization, they have the ability to create and simplify complex political narratives by employing primarily the categories of Shops, Text, and Stacked Stills based on Milner's (2012) Taxonomy of Meme Collectives. The memes' humor signifiers were mainly intertextuality, parody, and binary opposition which highlighted how memes are contextual in nature and use exaggeration and opposing concepts to elicit humor. On the other hand, the memes vary in their respective denotations as well as in their connotations which often point to humanization and discreditation. Lastly, for the memes' propaganda characteristics, they possess all 10 of Walton's (1997) propaganda characteristics while the audience perceived 9 out of 10 through the conducted survey. This proves that memes do have the potential to be used as tools for propaganda because of their inherent manipulation of complex political narratives which are furthered through the use of humor.
\end{abstract}

Keywords: Memes, Propaganda, Semiotics, Politics, Digital Media

\section{Introduction}

In the last decade, digital media have been ranked as the second most used media platform in the world next to broadcast media (Wagstaff, n.d.). In Southeast Asia alone, 641 million people used the internet in 2017, and that 51\% of them are active monthly users (Hollander, 2017). This means that $51 \%$ of Southeast Asians get immersed with digital media content which ultimately describes the kind of power digital media has, not only towards the Asian society but also in the whole world- an immense influence on the people, and their behavior. In other terms, media can elicit any kind of action from the people whether it be fear, hate, idolatry, or even fanaticism. One reason for this power is the language that it uses. Media as an institution has always been a melting pot of interesting linguistic phenomena for it is responsible for the language that people get acquainted with (Belle, 1995). This results in the shaping of the language that people use, which eventually is reflected in 
how advertisements, social media platforms, TV networks, and others, use a certain dialect or language (Belle). Such language then plays a crucial role in offering news and information about cultural, social, and political issues in a certain society (Belle).

With the power of influence at hand, any kind of media (e.g. broadcast, printed, and digital) has the capability of organizing people to form a community. Digital media has led to the creation of an online community with its own culture such as humorous videos and images called Memes. Memes have taken over the web, even being labeled as the defining characteristic of the internet (Rintel, 2014) due to their ability to communicate messages through a humorous perspective that gains virality on the internet. Something that is essential and powerful in spreading an ideology and strengthening a community's solidarity.

\section{The Political Arena: Duterte Administration}

With all the controversy surrounding the current administration of President Rodrigo Duterte, Filipinos have taken their views and opinions on social media particularly Facebook. Polarizing opinions exist on the internet which has often resulted in people being tagged as either DDS or Dilawan (which refers to Duterte's major political party opposition named the Liberal Party). These polarizing opinions expressed on Facebook can be found in various forms such as long posts, videos, and one-liners, but netizens always find themselves coming across memes of the current administration. These are called political memes which are memes that focus on the political arena. According to Pleviriti (2014), political memes satirize politics; It aims to provide a humorous but critical assessment of recent political issues but are often overlooked and not taken seriously. This is because the majority of people only see memes as trivial and solely for entertainment (Plevriti, 2014). Supposedly, as Calimbo (2016) espouses, they are representations of popular culture which come from a perspective of oral tradition and folklore while politics is found rooted in modernity and literacy (Van Zoonen, 2005 as cited in Plevriti, 2014).

2.1. Language of Memes

Looking closely, Internet memes typically represent and carry ideas, opinions, and arguments. According to De la RosaCarillo (2015), memes have a "visual and succinct nature" (p. 22). This visual and succinct nature translates into their virality exhibited on the internet, which determines the life of a meme. It relies on the reusing and remixing of netizens which is a direct parallel of verbal languages (De la Rosa-Carillo). As such, he argues that the virality of memes depends on their message-carrying capabilities that, as what Belle (1995) specifies of media language, are cultural, social, and political in nature, and even extending to emotional as well.

Memes are speech acts (Grundlingh, 2017). From a pragmatic perspective, memes are illocutionary acts because though they do not adhere to the traditional written communicative processes, they utilize the foundational aspect of a speech act which is a creator, a writer/speaker, and a receiver, a reader/hearer (Grundlingh). Grundlingh's study revealed that for the receiver or audience to fully engage and understand the meme, there must be a degree of literacy, schema or background knowledge, and/or context. Thus, memes can carry complex messages and can function just like other languages can as long as there is a common ground between the creator and the receiver.

Milner (2012) reported that memes are a gateway to opening online discussions to people as part of participatory culture. This culture consists of three kinds: creators, distributors, and viewers (Plevriti, 2014). Meme creators aim to produce content mainly for self-expression and exposing unrighteous acts of politicians, as well as reveal injustices in socio-political issues; promote certain advocacy, stance, and/or cause. On the other hand, distributors share political memes for social interaction and community building resulting in solidarity with other people. Lastly, viewers of memes see them as a tool to gather information and be entertained. Since memes are produced by people, they also represent the popular culture (Calimbo, 2016), which consequently engages the audience in online discussions. Thus, memes facilitate cultural participation through the combination of images and texts eliciting humor, while forwarding an opinion or an argument whether that argument is cultural, political, social, or emotional in nature.

Both Calimbo (2016) and Hristova (2014) provided a unique way of understanding memes. While Calimbo claims that memes can be used both to serve as an avenue for political commentary and to deconstruct the normalized political violations of Filipino politicians, Hristova highlighted the importance of memes' virality as a political tool. However, neither addressed the audience's perspective towards these memes and their participation in a movement or an issue. This opens a new semiotic research opportunity on memes through a careful analysis of their message, the degree or extent of audience reception, and the impact of memes from a societal perspective. This is true especially in the political arena of the Philippines, but few studies have been made on Philippine political memes, specifically on the Duterte Administration and its recent controversies. This research aims at bridging that gap and bringing forth a new understanding of memes on how they function in the Philippine political arena, specifically as tools for propaganda.

\subsection{The Political Arena: Memes as Tools for Propaganda}

It is clear that the word propaganda has earned a negative connotation today. Lasswell (1927) provides an in-depth analysis of what propaganda means: a "management of collective attitudes by the manipulation of significant symbols," (p. 627). He explains that the attitude towards the word comes from the fact that propaganda persuades its audience to act following patterns of valuation through signification, which aims to solidify a certain attitude towards a certain issue (Lasswell), or in other words, crystallization of an idea. 
Despite all the negative connotations garnered by 'propaganda' through the years, Walton (1997) argues that the word still has a mixed quality. Although propaganda raises some ethical questions due to its manipulative nature, it can still be used to forward an agenda for good causes. Another negative aspect of propaganda is that oftentimes, it can contain illogical reasoning because it aims to appeal to people or ad populum (Walton) which usually target people's emotions to easily and effectively persuade them. Another term for this is emotionally-charged phraseology (Hurley, 1994 as cited in Walton). Generally, there are two types of ad populum arguments, the indirect approach and the direct approach. In the indirect approach, much of the statements are aimed towards the crowd individually, while in the direct approach, the statements made are usually made to feel that the individual belongs in a much bigger crowd with a much bigger purpose- to be united as one which is reminiscent of the capability of memes to create solidarity within its community of users (Plevriti, 2014). Individuals who dare to go against the conclusion of the statement risk their once gained acceptance and unity with the crowd (Walton).

Stiver (2012) highlights how media is the monster that society has created through technological advancements specifically, modern propaganda. Stivers specifies that modern propaganda requires a whole of society whose public opinion overpowers its private opinion or a meme characteristic called virality. This is the process Lasswell (1927) calls the crystallization of ideas. Through this, society creates a common and well-known opinion, one that is accessible to the public, and follows that opinion henceforth. This is the glue that holds society together, that of which is created by sociological propaganda; "Propaganda manipulates us before it attempts to persuade us rationally" (p. 207). Thus, it is clear that there is already a culture of propaganda as it is evident in both the political field and the social field, the latter being advertisements and the like.

Internet political memes have been proved to successfully serve as an avenue for people to voice out their opinions, commentary, and critique of the political arena as a whole. Still, several studies have found memes' impact to be negative such as McClure (2016) in which he claimed that memes can be used as propaganda banking on the premise that they cannot be used as a tool for critical thinking. There is also Hristova (2014) which revealed that memes' strength of virality, remixing, and anomalous juxtaposition is also their downfall in their usage as a political tool as they lose meaning and credibility as they are remixed and reshared. This establishes the question of just how influential memes are, specifically Philippine internet political memes, in propagating certain ideologies and opinions, and how they are received by the audience.

In view of the foregoing, this research was aimed at bridging the gap on the linguistic study of memes by providing an analysis on audience perception which would enable a wider and deeper look at how people receive the message/ideology. This is especially true in the Philippine context where only Calimbo (2016) focuses on its linguistic aspect, as well as Varona's study on The Role of Internet Memes in Public Discourse on the 2013 Pork Barrel Case in the Philippines which has the same conclusion as Milner (2012): memes enable public participation (Varona, n.d. as cited in Calimbo 2016; Milner, 2012). Thus, this research sought to further the linguistic analysis of Philippine internet political memes and add a new perspective on how memes function in the political arena specifically as tools for propaganda.

2.3. Research Questions

1. How are the memes linguistically and visually organized?

2. What do the memes mean in terms of the following:

a. The memes' humor signifiers?

b. Denotation and connotation?

3. What propaganda characteristics are present in memes?

4. How are the memes as tools for propaganda perceived by the audience?

\section{Methods}

\subsection{Research Design}

This study employed a mixed-methods approach towards a multidimensional understanding of Philippine internet political memes. Semiotic analysis was first conducted to examine 60 political memes using Milner's (2012), Berger's (2004), Barthes' (1986), and Walton's (1997) frameworks. This was complemented by the survey approach to determine how the audience perceived memes as tools for propaganda.

\subsection{Study Corpus}

A total of 60 memes were collected from July 2016 to December 2018 which encapsulated Duterte's first two years in office. Two memes per month were collected, one anti-Duterte meme and one pro-Duterte meme to ensure the unbiasedness of the study. Each meme group has one meme per month all of which were chosen randomly at Facebook, from pages such as but not limited to MOCHA USON BLOG and For the Motherland - Sass Rogando Sasot, two known Pro-Duterte Facebook pages, and Silent No More PH and Malacañang Events and Catering Services which are known to be Anti-Duterte Facebook pages.

\subsection{Research Instruments}

A survey composed of $10 \%$ of the data collected, which totaled in 6 memes, were subjected to evaluation by 60 participants. The assessment was done based on 10 statements that reflect the features of propaganda according to Douglas Walton's (1997) Characteristics of a Propaganda. The questionnaire design was guided by Gideon (2012) and was validated 
by three experts, two Doctors of Philosophy in English Language Studies and one Doctor of Philosophy in Applied Linguistics.

\subsection{Research Participants}

The participants of the study consisted of 60 respondents, chosen randomly. They were divided into three groups according to their age including 20 young adults of 18 - 35 years old, 20 adults aged 36 - 55, and finally, 20 elders of 55 and above based on Yarlagadda, Murthy, and Prasad's (2014) study on human age group classification.

3.5. Data Analysis

The analysis of the data started with a content analysis using Milner's Taxonomy of Meme Collectives (2012), the Semiotic Theory of Humor by Berger (2004, as cited in Calimbo, 2016), Roland Barthes's Denotation and Connotation (1986), and Walton Douglas's (1997) Propaganda Characteristics. First, the 60 memes underwent the assessment of their linguistic and visual organization according to Milner (2012) which assessed how the memes were able to create meaning according to the arrangement of their physical elements. Next, the memes' humor signifiers were identified using Berger (2004, as cited in Calimbo, 2016) and were subjected to the analysis of their meanings in accordance with Barthes (1986). These meanings were analyzed through the lens of political propaganda and were identified if the content analysis of the memes matched the 10 aspects of the Characteristics of a Propaganda.

To summarize the findings of the content analysis for the memes' linguistic and visual orientation, humor signifiers, and propaganda characteristics, a frequency distribution was utilized.

Next, the data that were culled from the survey underwent the same statistical treatment of frequency distribution and were later on subjected to the statistical treatment of weighted mean. This determined the equal average of the results of the survey which utilized a 4-point Likert scale. Each weighted mean was then subjected to a verbal interpretation of Strongly Agree, Agree, Disagree, and Strongly Disagree.

\section{Findings and Discussion}

\subsection{Linguistic and Visual Organization of the Memes}

Table 1. Linguistic and Visual Organization based on Milner's (2012) Taxonomy of Meme Collectives

\begin{tabular}{|c|c|c|c|c|}
\hline & \multicolumn{2}{|c|}{ Total } & Overall & Rank \\
\hline Remixed & Anti & Pro & & \\
\hline \multicolumn{5}{|l|}{ Single } \\
\hline Annotated Still & 9 & 4 & 13 & 5 \\
\hline Demotivationals & 1 & 3 & 4 & 9 \\
\hline Macros & 8 & 7 & 15 & 4 \\
\hline Quotes & 3 & 6 & 9 & 7 \\
\hline Shops & 21 & 9 & 30 & 1 \\
\hline Text & 10 & 9 & 19 & 3 \\
\hline \multicolumn{5}{|l|}{ Stacked } \\
\hline Rage comics & 1 & 1 & 2 & 11 \\
\hline Stacked stills & 8 & 13 & 21 & 2 \\
\hline \multicolumn{5}{|l|}{ Stable } \\
\hline Drawings & 2 & 6 & 8 & 8 \\
\hline Graphs & 0 & 0 & 0 & 12 \\
\hline Memes IRL & 0 & 0 & 0 & 12 \\
\hline Photos & 1 & 3 & 4 & 9 \\
\hline Screenshots & 4 & 6 & 10 & 6 \\
\hline
\end{tabular}

Table 1 shows the total of the analyzed memes according to Milner's (2012) Taxonomy of Meme Collectives. This refers to the meaning-making processes of the memes. It was revealed that the 60 analyzed memes are not constrained in their categories but are a hybrid of the remixed and stable images proving that, as products of pop culture, memes have transcultural flows meaning they do not adhere to any national, ethnic, cultural, or linguistic boundaries (Shinhee \& Moody, 2012). The process in which the memes create meaning flows from one category to another allowing for a more complex message to be received and decoded by the audience. 


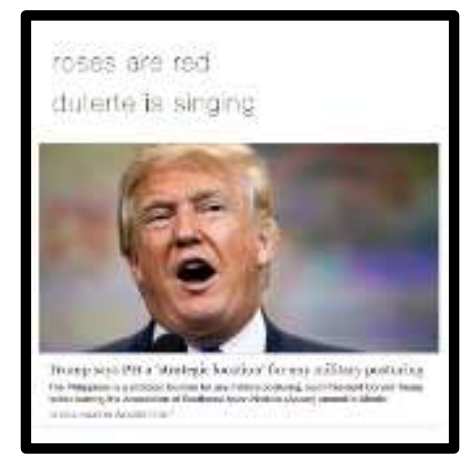

Figure 1. 2017 Anti-Duterte Meme \#11

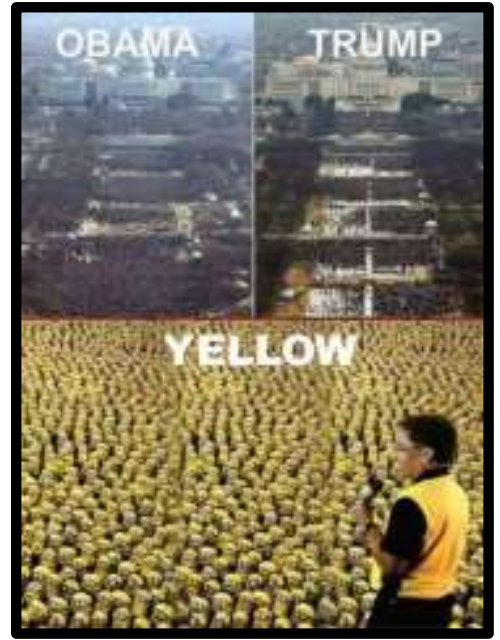

Figure 2. 2017 Pro-Duterte Meme \#1

In Figure 1, the first category is a Text. Two poetic lines were added as a primary clause of the meme which was then combined with a screenshot of the news making it a hybrid of a Text and a Screenshot. When put together, the two can now be considered as a Stacked Still which created a rhyming scheme eliciting a poem-like structure when the first two poetic lines are read together with the news headline. The way these images are combined now creates a narrative through the use of a poetic structure.

According to Milner (2012), Shops are the types of memes that have undergone a photo editing software called Photoshop that changes and/or adds meaning to the photo. This means that most of the Philippine internet political memes have undergone photo manipulation to create a narrative that supports the hidden meaning. As Figure 2 shows, Mar Roxas standing in front of a crowd of minions adds to the metonymy of the word "Yellow' and the rest of its connotations which can be found in the Denotation and Connotation discussion.

The second most frequent category is Stacked Stills referring to the combination of two or more photos stacked together to form a narrative following the sequence the images were placed upon. This indicates that with the 21 occurrences, the analyzed Philippine internet political memes require two or more panels to effectively create meaning that is based on the arrangement of the panels or the sequences as Figure 2 shows.

Third on the most frequent category would be Text which indicates that an image alone cannot properly convey the intended message. As proved by Milner (2012) and Grundlingh (2017), the audience cannot appreciate the message of the meme if they are not able to relate to it or if they do not have a schema of the issue being portrayed. Such clarity that a text provides helps the audience to relate to the meme more and therefore, be able to understand the message and participate in discussions.

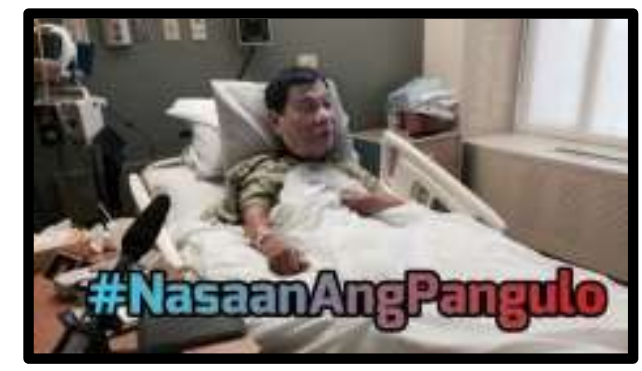

Figure 3. 2017 Anti-Duterte Meme \#8

As Figure 3 shows, the photoshopped head of Duterte in the meme implies that he is the one on the hospital bed and with the hashtag \#NasaanAngPangulo (\#WhereIsThePresident). It creates a narrative that the president is missing because he is in the hospital, bedridden. This kind of manipulation of the linguistic and visual elements of the meme creates a simplified narrative that is easy to digest. According to Olsen (2018), simplifying a complex political narrative has the tendency to create and spread misinformation. True enough, none of the rumors that the president has terminal illness were confirmed (Calonzo \& Yap, 2018).

In summary, the memes' linguistic and visual organization cannot be contained in a rigid category, rather its arrangement of elements flows into multiple categories that effectively generate a manipulated meaning. As De la Rosa-Carillo (2015) 
argues, memes are visual and succinct. This manipulated meaning results in the creation of a narrative that often simplifies a political context or issue that can result and be used as a tool for disinformation.

4.2. The Meaning of Memes: The Meme's Humor Signifiers

Table 2. Memes' Humor Signifiers

\begin{tabular}{|l|c|c|c|c|}
\hline & \multicolumn{2}{|c|}{ Total } & Overall & Rank \\
\hline $\begin{array}{l}\text { Humor } \\
\text { Signifiers }\end{array}$ & Anti & Pro & & \\
\hline Metaphor & 1 & 1 & $\mathbf{2}$ & $\mathbf{5}$ \\
\hline Metonymy & 3 & 2 & $\mathbf{5}$ & $\mathbf{4}$ \\
\hline Intertextuality & 20 & 20 & $\mathbf{4 0}$ & $\mathbf{1}$ \\
\hline Parody & 18 & 17 & $\mathbf{3 5}$ & $\mathbf{2}$ \\
\hline $\begin{array}{l}\text { Binary } \\
\text { Opposition }\end{array}$ & 9 & 6 & $\mathbf{1 5}$ & $\mathbf{3}$ \\
\hline Puns & 0 & 1 & $\mathbf{1}$ & $\mathbf{6}$ \\
\hline Synecdoche & 0 & 1 & $\mathbf{1}$ & $\mathbf{6}$ \\
\hline
\end{tabular}

Table 2 shows the frequency of the humor signifiers found in the 60 Philippine internet political memes. Among the significantly highest were Intertextuality with 40 occurrences, Parody with 35 occurrences, and Binary Opposition whose occurrence totaled 15.

Intertextuality, with 40 occurrences, proves that memes are highly contextual in nature. The incongruence in their humor is always based on another issue, event, or situation which reaffirms the notion that one cannot understand the meme if one does not have prior knowledge of the background (Grundlingh, 2017). For example, Figure 4 shows Sarah Duterte, Noynoy Aquino, Rodrigo Duterte, and Mar Roxas on the same campaign float. At first glance, this meme does not elicit any humor, but with the knowledge of the current context of Duterte being against PNoy and Mar Roxas because they belong to the Liberal Party, the audience now understands that there is a binary opposition going on. This gives the notion that intertextuality often elicits another form of humor signifier.

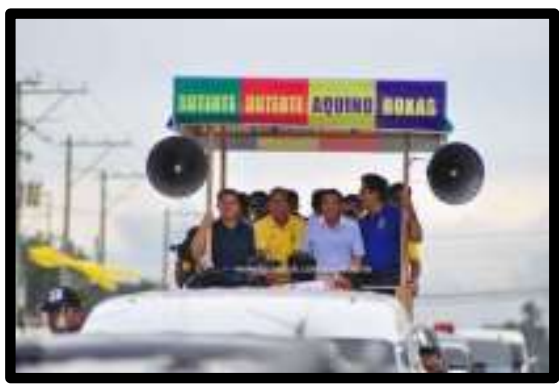

Figure 4. 2017 Anti-Duterte Meme \#10

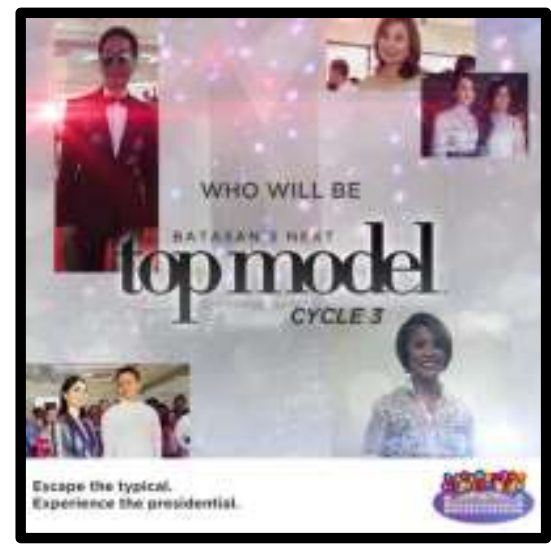

Figure 5. 2018 Anti-Duterte Meme \#7

Parody with 35 occurrences, indicates that memes satirize the issues portrayed. Parodies also tend to exaggerate, define, and highlight absurdities of political contexts which reaffirm the claims of McClure in his study that memes have the process of "amplification through simplification" (McCloud, 1994 as cited in McClure, 2016) (p.292), reminiscent of what propaganda is. Figure 5 is a parody of the famous television reality show called America's Next Top Model wherein it features amateur models vying for the position of the top model. In the meme, the word America is replaced with "Batasan" referring to the Batasan Hills, where the legislative House of Representatives of the Philippines is located. The addition of the famous politicians' photos furthers the contrastive element that influences the audience to associate the politicians with amateur models of a reality TV show. Therefore, it is realized that this meme is in reference to President Duterte's 2016 State of the Nation Address (SONA), deemed to have turned into a fashion show for politicians. It further connotes that SONA has become a spectacle due to the media's sensationalism of the politicians' luxurious clothes rather than Duterte's actual speech. Parody imitates and violates the "code of authorial identity" (Berger, 2004, p.16) and uses this code violation to ridicule another situation making the humor signifiers of Figure 20 Parody and Intertextuality. 
Lastly, binary opposition is the third most frequent humor signifier found with 15 occurrences. As earlier discussed, binary oppositions happen when two concepts of the opposite meaning are present in the meme. These also exhibit a form of irony just as what can be analyzed in Figure 6.

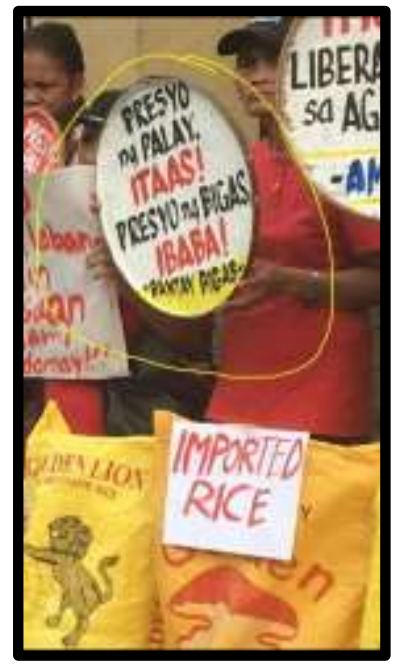

Figure 6. 2018 Pro-Duterte Meme \#2

Binary opposition is exhibited by the notion of the protester wanting high prices for unmilled rice and low prices for milled rice which is not in accordance with the basic economics law of supply and demand because the farmers would not earn any profit. It is ironic considering that the protester is trying to protest for the sake of both the producers and consumers. Furthermore, the ironic humor connotes a weakening of the cause that they are trying to forward.

Other humor signifiers include Metaphor with 2 occurrences, Metonymy with 5 occurrences, Puns with 1 occurrence, and Synecdoche with 1 occurrence which is indicative that humor in memes utilizes forms of figures of speech, making it easier to elicit humor and at the same time, receive the messages effectively as humor acts as a vehicle.

The humor signifiers of the memes produce a relationship that is found exclusively. This relationship ultimately results in "amplification through simplification" (McCloud, 1994 as cited in McClure, 2016, p.292) produced by the narrative sequences. What amplifies the simplified message effectively is the humor elicited with each visual and linguistic organization. However, humor signifiers of the memes cannot decode the message since memes are heavily contextual in nature. As Calimbo (2016) states, in order to decode the memes' full implications, one must recognize the basic properties of memes because a structuralist semiotic perspective limits the interpretation of the meme to the linguistic and visual elements and organization only.

4.3. The Meaning of Memes: Memes' Humor Signifiers Denotation and Connotation

Table 3. Themes/Issues of Pro-Duterte Philippine Internet Political Memes

\begin{tabular}{|c|}
\hline $\begin{array}{c}\text { Pro-Duterte Philippine Internet Political } \\
\text { Memes }\end{array}$ \\
\hline Dilawans / Liberal Party \\
\hline Duterte as Strong man \\
\hline Anti-movements \\
\hline Comparison of Duterte to other presidents \\
\hline Critics \\
\hline Marcos \\
\hline Rappler \\
\hline
\end{tabular}




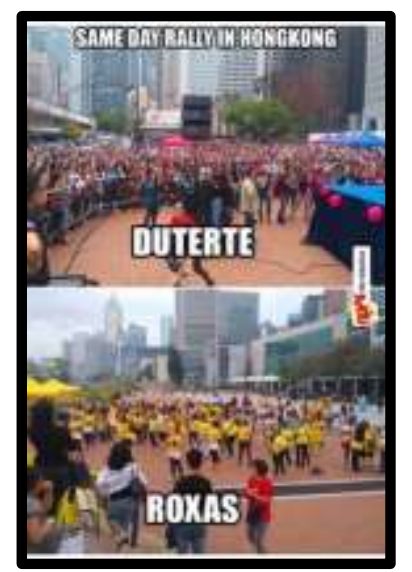

Figure 7. 2016 Pro-Duterte Meme \#4

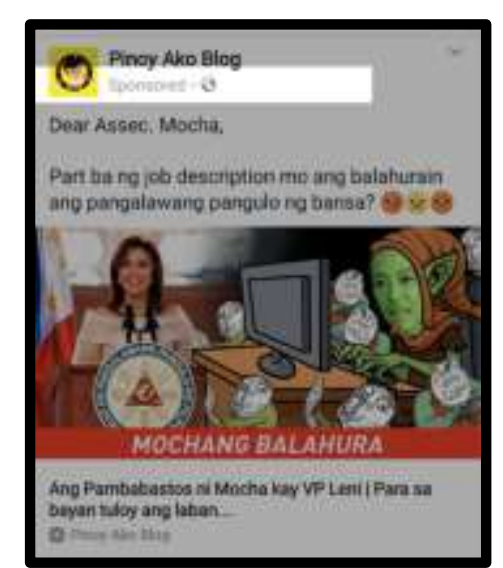

Figure 8. 2018 Pro-Duterte Meme \#1

The contrast in figure 7 highlights the meme's connotation as to how Roxas's rally seemed staged while Duterte's was more candid and genuine. Furthermore, the lack of unified shirt color in Duterte's rally in contrast with Roxas's wherein all of them were wearing yellow, connotes that Duterte is a "poor-man's" president and makamasa as what his campaign slogan was all about. Thus, this binary opposition type of humor signifier which was elicited by the linguistic and visual organization of Stacked Stills made Duterte more likable by humanizing him using this meme.

Figure 8 , on the other hand, tells the narrative that the Liberal party uses money to spread propaganda and deceive people. The simple highlighting of the word 'sponsored' emits a metonymy giving it a new meaning; that the post was paid by someone from the liberal party to spread undesirable news about Mocha Uson. This strengthens the speculations that Liberal party supporters and Duterte critics were just paid to further hate and oppose the current administration.

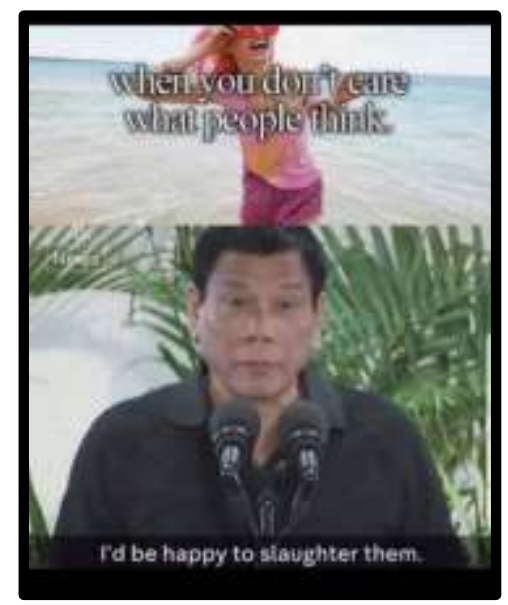

Figure 9. 2016 Pro-Duterte Meme \#5

Another prevalent theme in the Pro-Duterte memes was Duterte's strongman qualities. As exhibited in Figure 9, it is denoted that Duterte just says what he wants to say and does whatever he pleases to do. Considering the meme's context, he is saying that he would be happy to slaughter drug addicts and corrupt politicians which, connotatively, strengthens his already established image of a strongman. It further connotes the humanization of Duterte as he is placed in a normal social context with a response that any laypeople could make and be passed off as a joke, placing Duterte on equal footing as that of laypeople. It normalizes that kind of uncharacteristic presidential behavior.

Overall, Pro-Duterte memes often connote discreditation of the Liberal Party and its members to disrepute them in political discourses. The same is also true for memes that focus on themes/issues on critics and Rappler. Memes that show Duterte's strongman characteristics while reaffirming his tough leadership, when put in social contexts that laypeople experience, humanizes the president and therefore, becomes a way for people to relate to him; furthering support for Duterte which is also true for memes whose themes/issues lie on the comparison of Duterte to other presidents. Meanwhile, for memes that depict anti-movements, it is evident that they can instantly discredit whatever the movement is fighting for. 
Table 4. Themes/Issues on Anti-Duterte Philippine Internet Political Memes

\begin{tabular}{|l|}
\hline Anti-Duterte Philippine Internet Political Memes \\
\hline China \\
\hline Uncharacteristic president \\
\hline Terminal disease \\
\hline Likened to other presidents \\
\hline PNoy administration \\
\hline Incompetent Duterte administration \\
\hline Rallying \\
\hline De Lima \\
\hline Dutertards \\
\hline SONA \\
\hline Mocha Uson \\
\hline
\end{tabular}

Figure 10 is in reference to the promise Duterte made during one of his speeches wherein he said that he would Jet Ski his way to China if China will not recognize the legitimate claim the Philippines has on the Spratly Island. This meme pokes fun at the president's promise by mocking him that he should practice how to Jet Ski because it seems like all efforts to protect the Spratleys Island from Chinese invasion are failing. The linguistic and visual organization of Shops, Macros, and Annotated Stills work together to create a connotation that implies the inability of Duterte to protect the Philippines from China.

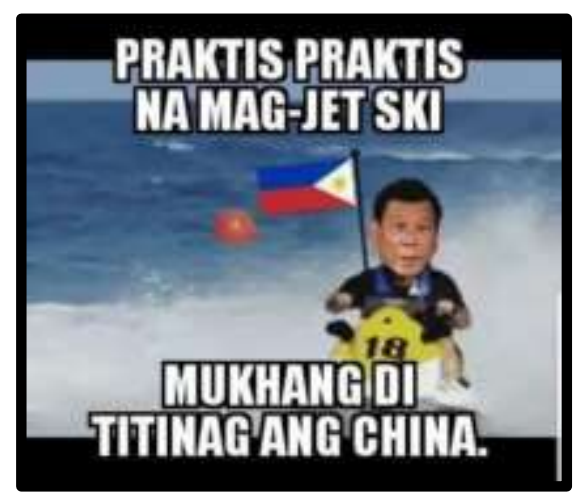

Figure 10. 2016 Anti-Duterte Meme \#1

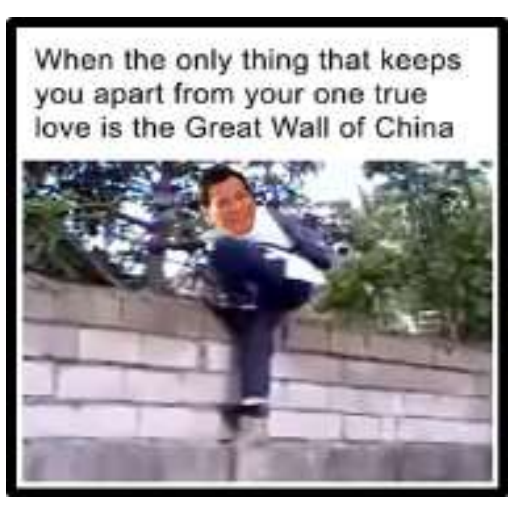

Figure 11. 2018 Anti-Duterte Meme \#4

Figure 11 shows a man going over a wall with Duterte's face photoshopped. Accompanied with the caption, it paints him as obsessed and in love with China, when all he wants is a good relationship with a neighboring super country for the economic growth of the Philippines. Furthermore, this meme connotes that Duterte is willing to go through numerous heights just to maintain a strong relationship with China.

Another theme/issue is with memes that show how Duterte acts uncharacteristically that of a president. In Figure 12, the audience is met with opposing statements by Duterte talking about how God made him president and then saying that God is stupid. This meme shows how Duterte backtracks his statements which are an unlikely characteristic for a president. It further implies that Duterte will play any kind of man that favors him the most. Thus, he cannot be trusted in so far as being a president. It connotes discreditation of Duterte for all the work that he is doing for the Philippines, encouraging the audience to not trust and support Duterte. 


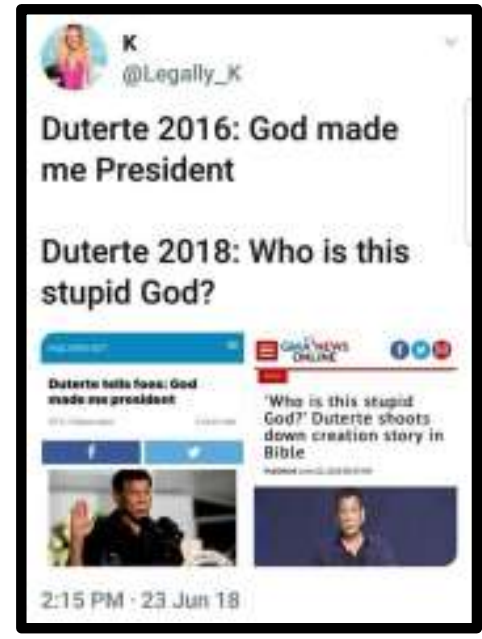

Figure 12. 2018 Anti-Duterte Meme \#6

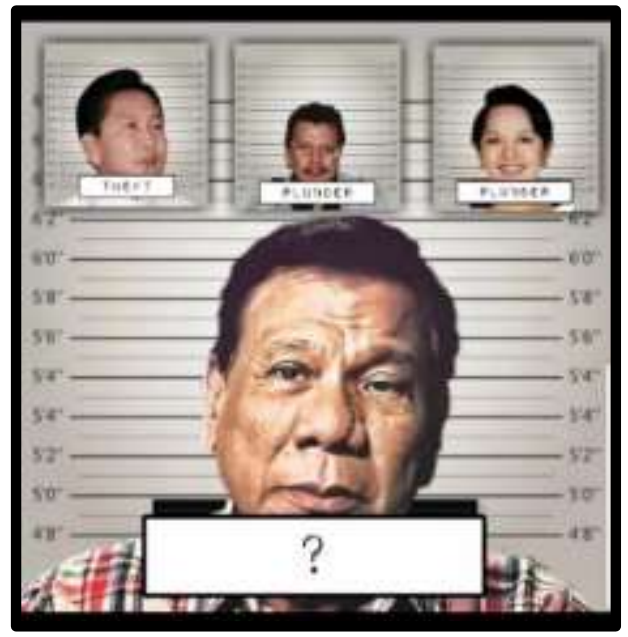

Figure 13. 2016 Anti-Duterte Meme \#3

Another theme/issue would be Duterte being likened to presidents. Figure 13 likens Duterte to past controversial presidents, such as Ferdinand Marcos, and with the usage of '?' as the code violation, gives the notion that he is just as bad as them. This connotes that Duterte is the same as these former presidents who do not have a good track record with the people. Furthermore, this means that Duterte is already in line with them, he is on the same path as them.

Overall, these Anti-Duterte memes indicate the underlying goals to discredit Duterte as a president and show his incompetencies in running the country. The memes which were premised upon themes/issues of China show the sudden shift of Duterte from his strongman persona to that of friendlier towards China which means that Duterte should not be trusted and supported. The same is also true for memes whose themes/issues are about his terminal disease, uncharacteristic president, the incompetent Duterte Administration, and likened to other presidents.

In summary, often both Pro-Duterte and Anti-Duterte memes connote more than what the literal meaning meant, with underlying goals like that of humanization and discreditation. With the use of primary humor signifiers intertextuality, parody, and binary opposition, the hidden messages of the memes are effectively received by the audience as the political context and/or issue is now simplified (McClure, 2016). Moreover, the simplified message digested by the audience allows them to relate to the meme more, encouraging them to participate in the meme culture which helps them in community building that strengthens their solidarity (Plevriti, 2014) with their respective groups. Thus, there is an inherent mechanis $m$ in the memes which allows them to be tools to further the dichotomy between Dilawans and DDS as these memes facilitate an echo-chamber-like process and are effective in crystallizing an attitude as what Lasswell (1927) said about propaganda.

4.4. Evaluation of Memes as Tools for Propaganda: Content Analysis

Table 5. Propaganda Characteristics

\begin{tabular}{|c|c|c|c|c|}
\hline & \multicolumn{2}{|l|}{ Total } & \multirow[t]{2}{*}{ Overall } & \multirow[t]{2}{*}{ Rank } \\
\hline & Anti & Pro & & \\
\hline Dialogue Structure & 30 & 30 & 60 & 1 \\
\hline Message Content & 30 & 30 & 60 & 1 \\
\hline Goal-Directed Structure & 21 & 25 & 46 & 3 \\
\hline Involvement of Social Groups & 11 & 12 & 23 & 8 \\
\hline $\begin{array}{l}\text { Indifference to Logical } \\
\text { Reasoning }\end{array}$ & 15 & 18 & 33 & 7 \\
\hline One-Sided Argumentation & 25 & 17 & 42 & 5 \\
\hline $\begin{array}{l}\text { Involvement of Persuasion } \\
\text { Dialogue }\end{array}$ & 3 & 8 & 11 & 10 \\
\hline Justified by Results & 3 & 13 & 16 & 9 \\
\hline $\begin{array}{l}\text { Emotive Language and } \\
\text { Persuasive Definitions }\end{array}$ & 20 & 19 & 39 & 6 \\
\hline Eristic Aspect & 19 & 25 & 44 & 4 \\
\hline
\end{tabular}

According to Table 3, the two most frequent propaganda characteristics observed were Dialogue Structure and Message Content which are present in all of the 60 memes analyzed. 
Dialogue Structure refers to the communicative discourse between people while Message Content refers to any kind of form that propaganda can take shape in. All memes have the characteristic of a Dialogue Structure because they are created by a proponent to communicate a message towards the recipients. As Grundligh (2017) explains, memes are an illocutionary act, they carry messages directed towards receivers. Memes have the characteristic of a message content because they take the primary form of images to embody these messages, as well as humor. Therefore, these two characteristics are inseparable when it comes to memes since they complement each other. As stated in the memes' linguistic and visual organization, both elements work together to form a message masked in humor. The form of the memes in and of themselves is a characteristic of what propaganda is.

Rank 3 is Goal-Directed Structure which is defined for its message to support either the interest of a group or the group itself and vice versa. The connotations of the memes have underlying goals such as to humanize and discredit, proving that memes do have the inherent structure focused to support/discredit politicians and issues. It is important to note that the goals that memes posit are always a representation of a much bigger message/ideology that, as a tool for propaganda, also aims to manipulate the audience subconsciously. In the words of Stivers (2012), "Propaganda manipulates us before it attempts to persuade us rationally" (p. 207) which is also in rank 7 as the most frequent propaganda characteristic in the memes called Indifference to Logical Reasoning. This characteristic is often accompanied by rank 5 One-Sided Argumentation.

4.5. Evaluation of Memes as Tools for Propaganda: Audience Perception

Table 6. Overall Audience Perception on Memes as Tools for Propaganda

\begin{tabular}{|l|l|l|}
\hline & Total & Verbal Interpretation \\
\hline $\begin{array}{l}\text { 1. I understand the meme's } \\
\text { background (the situation/the } \\
\text { issue behind the meme). }\end{array}$ & 3.3 & Strongly Agree \\
\hline $\begin{array}{l}\text { 2. I find the meme's message to } \\
\text { be funny and } \\
\text { appealing/interesting. }\end{array}$ & 2.99 & Agree \\
\hline $\begin{array}{l}\text { 3. I agree that the meme is in } \\
\text { support of a particular issue, } \\
\text { person, and/or social group. }\end{array}$ & 3.04 & Agree \\
\hline $\begin{array}{l}\text { 4. I agree that the meme } \\
\text { includes/represents a particular } \\
\text { person and/or social group. }\end{array}$ & 3.17 & Agree \\
\hline $\begin{array}{l}\text { 5. I agree that the meme is } \\
\text { unreasonable/ irrational. It does } \\
\text { not make any sense. }\end{array}$ & $2.3 \mathrm{~d}$ & Disagree \\
\hline $\begin{array}{l}\text { 6. I agree that the meme is } \\
\text { biased to one group. It only } \\
\text { supports one side of the } \\
\text { situation/issue. }\end{array}$ & 2.97 & Agree \\
\hline $\begin{array}{l}\text { 7. I agree that the meme is } \\
\text { persuasive or convincing. }\end{array}$ & 2.91 & Agree \\
\hline $\begin{array}{l}\text { 8. I agree that meme presents a } \\
\text { problem/s that is biased or is in } \\
\text { support of one side. }\end{array}$ & 2.99 & Agree \\
\hline $\begin{array}{l}\text { 9. I agree that the meme uses } \\
\text { words that are emotionally } \\
\text { engaging and persuading. They } \\
\text { use funny words. }\end{array}$ & 2.96 & Agree \\
\hline $\begin{array}{l}\text { 10. I agree that the meme is } \\
\text { effective in disproving anti- } \\
\text { Duterte / DDS arguments. It } \\
\text { can instantly shut down anti- } \\
\text { Duterte / DDS arguments. }\end{array}$ & 2.47 & \\
\hline
\end{tabular}

In summary, based on audience perception, memes do have the capability to become effective tools for propaganda as they possess 9 out of 10 propaganda characteristics identified by Walton (1997). Only one propaganda characteristic returned with negative results which were Indifference to Logical Reasoning, meaning that even though memes have the tendency to become illogical due to the simplification process, the audience still perceives them as logical. Factors that affected this discrepancy could be that memes, as tools for propaganda, use logical reasoning to effectively persuade people. Another 
would be that memes employ the propaganda characteristic of Dialogue Structure; even though a meme is illogical, the audience still perceives it as logical, in line with Stivers's (2012) claim that propaganda firstly persuades before rationally convincing people. This shows that Filipino society needs to improve its media literacy especially with the growing number of Filipinos using social media.

\section{Conclusion}

It is evident that as pop culture data, memes are transcultural; they do not respect the set social, cultural, historical, ethnic, and/or linguistic boundaries. This characteristic allows memes to be more effective in curating messages combined with their humor as a vehicle to further their messages, making them understandable and digestible by watering down complex political issues. This makes those who participate in the meme culture prone to misinformation. Once this simplistic humorous message is received, its underlying message is received as well. These underlying messages have goals such as humanizing the political actor to either criticize or gain sympathy/support for them. They also connote a goal of discrediting the political actor or argument/idea portrayed. Furthermore, memes possess all ten of the propaganda characteristics which further justifies that while memes are a form of entertainment, they can be tools for propaganda. However, based on the conducted survey, it was revealed that the audience identified 9 out of 10 propaganda characteristics; they did not identify Indifference to Logical Reasoning as present which is a discrepancy compared with the content analysis. This indicates that according to audience perception, memes utilize logical reasoning which makes the audience understand the messages more effectively. At the same time, this can also indicate that the respondents have a low sense of media literacy as they still see memes as logical even though they are not.

Philippine internet political memes, as user-generated pieces of culture, then have the ability to relay hidden messages anchored on a specific goal, founded on a specific ideology. As memes are inherently viral, this virality becomes a boost for the messages they carry to be received by a large number of people, creating a sense of belongingness and solidarity through humor. As products of pop culture, memes are a way for a person, group, community, and even an institution to promote their opinions and stances on issues in the guise of entertainment and humor, making memes a perfect example of how political propaganda can take any form and shape. Therefore, even the simplest and entertaining media artifact can propagate different kinds of messages and ideologies.

This research aims to further people's understanding of memes and how these media artifacts can be so much more than what they seem. It shines a light on the rise of meme culture and the changes that it can bring to the political field. This goes to show that along with the changes that the 21 st technological century has brought, the way politicians and even social groups can forward their respective agendas have also changed. It is about time that the audience realizes that anyone with the intention and power can feed a group of people or even a whole community with illusions and lies that can lead to further manipulation of thoughts and actions. Therefore, it is needed in this modern era, for people to become aware of these manipulations, be critical of the kind of media they consume, and of course, fact-check the information that they come across with. It is time that the audience takes an active part in becoming the first line of defense against misinformation and disinformation because a properly informed citizen is an empowered citizen.

\section{References}

Barthes, R. (1964) Elements of Semiology, New York, The Noonday Press

Belle, A. (1995). Language and the Media. Annual Review of Applied Linguistics, 15, 23 - 41.

Berger, A. A. (1995). Semiotics and cultural criticism. In A. A. Berger (Ed.), Cultural Criticism, 4, 73 - 100.

Berger, A. A. (2004, June 17). Semiotic analysis. Retrieved from http://uk.sagepub.com/sites/default/files/upmbinaries/5171_Berger_Final_Pages_Ch apter_1.pdf.

Berger, A. A. (n.d.). Signs of humor: on the structure of laughter. Retrieved from culturestudies.pbworks.com/f/Semiotics+of+Humor+AAB.doc.

Calimbo, A. C. (2016). Deconstructing myths via humor: A semiotic analysis of Philippine internet political memes. CASS Langkit Journal, 6, 1-20.

Calonzo, A., \& Yap, C. (2018). Duterte says recent tests show he doesn't have a serious illness. Retrieved from Bloomberg: https://www.bloomberg.com/news/articles/2018-10-09/philippines-duterte-has-no-serious-illness-spokesman-says.

De la Rosa-Carillo, E. L. (2015, June 11). On the language of internet memes. Retrieved from UA Campus Repository: http://arizona.openrepository.com/arizona/handle/10150/556817

Grundlingh, L. (2017). Memes as speech acts. Social Semiotics. Advanced online publication. doi: $10.1080 / 10350330.2017 .1303020$.

Haddow, D. (2016). Meme warfare: how the power of mass replication has poisoned the US election. Retrieved from The Guardian: https://www.theguardian.com/us-news/2016/nov/04/political-memes-2016-election-hillary-clinton-donaldtrump.

Hollander, R. (2017). Southeast Asia could be a leader in mobile internet usage next year. Retrieved from Business Insider: https://www.businessinsider.com/southeast-asia-could-be-a-leader-in-mobile-internet-usage-next-year-2017-12.

Hristova, S. (2014). Visual memes as neutralizers of political dissent. Triple C, 12(1), 265-276. 
Lasswell, H. D. (1927). The theory of propaganda. The American Political Science Review, 21 (3), 627 - 631.

McClure, B. (2016). Discovering the discourse of Internet political memes. Adult Education Research Conference, 292 - 293.

Milner, R. (2012). The world made meme: Discourse and identity in participatory media. Retrieved from KU ScholarWorks: https://kuscholarworks.ku.edu/handle/1808/10256.

$\mathrm{Ng}$, A. (2018). Russial trolls targeted teens on Facebook with memes. Retrieved from CNET: https://www.cnet.com/news/russian-trolls-targeted-teens-on-facebook-with-memes/.

Olsen, D. (2018). How memes are being weaponized for political propaganda. Retrieved from Salon: https://www.salon.com/2018/02/24/how-memes-are-being-weaponized-for-political-propaganda/.

Plevriti, V. (2014). Satirical user-generated memes as an effective source of political criticism, extending debate and enhancing civic engagement. Retrieved from CCMPS Prize-Winning Dissertations (MA): https://warwick.ac.uk/fac/arts/theatre_s/cp/research/publications/madiss/ccps_13-14_vasiliki_plevriti.pdf.

Rintel, S. (2014). Explainer: what are memes? Retrieved from The Conversation: https://theconversation.com/explainerwhat-are-memes-20789.

Semiotics: The theory behind media literacy. (n.d.). Retrieved from http://courseweb.stthomas.edu/mjodonnell/cojo232/pdf/semiotics.pdf

Shinhee, J., \& Moody, A. (2012). English in Asian pop culture. Hong Kong : Hong Kong University Press.

Stivers, R. (2012). The media creates us in its image. Bulletin of Science, Technology \& Society, 203 - 212.

Wagstaff, J. (n.d.). Southeast Asian media: Patterns of production and consumption. Retrieved from Open Society Foundations: https://www.opensocietyfoundations.org/sites/default/files/production-consumption-20100212.pdf.

Walton, D. (1997). What is propaganda, and what exactly is wrong with it? Public Affairs Quarterly, 11(4), 383 - 412.

Wells, D. D. (2018). You all made dank memes: Using Internet memes to promote critical thinking. Journal of Political Science Education. Advanced online publication. doi:10.1080/15512169.2017.1406363. 